\title{
REVIEWS
}

Elwira Szychot ${ }^{1, \mathrm{~A}-\mathrm{F}}$, ANdrzej Brodkiewicz ${ }^{2, \mathrm{E}, \mathrm{F}}$, Jaroseaw Peregud-Pogorzelski ${ }^{3}$, E, F

\section{How Have Advances in Our Understanding of the Molecular Genetics of Paediatric Leukaemia Led to Improved Targeted Therapies for These Diseases?}

\author{
${ }^{1}$ Haematology and Oncology Department, Great Ormond Street Hospital for Children NHS Foundation Trust, \\ London, UK \\ ${ }^{2}$ Department of Pediatrics, Nephrology with Dializotheraphy and Management of Acute Poisoning, \\ Pomeranian Medical University, Szczecin, Poland \\ ${ }^{3}$ Department of Pediatrics, Hematology and Pediatric Oncology, Pomeranian Medical University, Szczecin, \\ Poland
}

A - research concept and design; $\mathbf{B}$ - collection and/or assembly of data; $\mathbf{C}$ - data analysis and interpretation;

$\mathbf{D}$ - writing the article; $\mathbf{E}$ - critical revision of the article; $\mathbf{F}$ - final approval of article; $\mathbf{G}$ - other

\begin{abstract}
The term "leukaemia" refers to a large and heterogenous group of diseases, with treatment response and outcome dependent on the specific type of malignancy. New molecular methods allow us to specifically evaluate the type of disorder, and provide treatment of necessary intensity. The aim of this review is to provide insight into the progress in leukaemia treatment that had been possible due to advances in molecular genetics over the last few decades. Those new sophisticated diagnostic methods have allowed us not only to predict patients' prognosis but also to provide a specific therapy depending on the molecular and genetic characteristics of patients. Our review is based on 25 articles regarding novel diagnostic and therapeutic methods as well as prognostic factors, released between 1992 and 2011. Those articles focus mostly on molecular and cytogenetic testing allowing revolutionary methods of patient classification and individual therapy for this highly heterogeneous group of disorders. Implementation of molecular genetic testing to evaluate the type of leukaemia allowed paediatric oncologists and haematologists to adjust the intensity of treatment, improve outcome, minimize toxicity of therapies and considerably lower the risk of side effects. In the last few decades there has been a great improvement in survival among children suffering from haematopoietic malignancies. Progress made in molecular genetics allowed the creation of new treatment protocols that are designed to maintain a high cure rate for children with leukaemia while reducing toxicity (Adv Clin Exp Med 2014, 23, 3, 469-474).
\end{abstract}

Key words: children, leukaemia, genes, targeted therapy.

Over the last few decades, significant advances in molecular biology have focused attention on leukaemia as a genetic disorder. The identification and characterization of molecular lesions associated with this haematological malignancy has led to advances in the classification and prognosis of leukaemia, which in turn has been useful in stratifying the patients for treatment purposes. Generally, stratification is a way of classifying patients using multi-factorial algorithms that assess their risk of relapse when specific therapies are used [1]. Developing a practical therapeutic stratification that allows accurate identification of disease response offers the potential to individualize adjuvant therapy and to minimize long-term adverse effects in a subgroup of survivors.

These processes are the most fully developed and have been the most successful in the diagnosis and treatment of acute lymphoblastic leukaemia (ALL), which represents the majority of children 
with leukaemia. The advances in the treatment of ALL over the past decades have been made by refining risk stratification and the use of existing chemotherapy schedules. This has improved overall survival from essentially zero in the 1950s and early 1960 s up to $65-90 \%$ in modern centres [1].

\section{ALL}

Acute lymphoblastic leukaemia (ALL) is the most common type of malignancy in children. It represents approximately $80 \%$ of all paediatric leukaemias [2]. ALL is a genetically and phenotypically heterogeneous disease. A histologic classification of ALL is mainly related to immunophenotype, which is based on flow cytometry assays with specific fluorescent antibody panels. ALL immunophenotypes are designated as pro-B (usually CD-10 negative infants, $3 \%$ of the cases); pre-B ( $80 \%$ cases) and T cell [1]. Infants and T-cell patients belong to a group of high-risk patients and are best treated on protocols that are designed for these particular diseases. Several clinical features have been identified to help define high-risk patients: age $<1$ year or $>10$ years, initial WBC $>50000$ cells $/ \mu \mathrm{L}$, and the presence of leukaemic blasts in the blood-brain or blood-testes sanctuary sites [3, 4].

Significant progress has been made in identifying molecular and cytogenic factors that are implicated in disease pathogenesis. These insights in turn have generated strategies for improving treatment outcome and minimizing the toxicity of therapies. The factors that are of critical importance in ALL include cytogenetic ploidy (the number of chromosomes or DNA content of ALL), chromosomal translocations, specific gene expression patterns, gene deletions and mutations.

\section{Cytogenetic Ploidy}

DNA content in a cell can be measured using flow cytometry equipment and DNA staining dye. This enables us to compare the average DNA content of the blast cells to normal diploid controls in a ratio known as a DNA index (DI). The DI of cells with a normal DNA content would be 1.0, while the DI for hyperdiploid cells would be $>1.0$ and hypodiploid cells would be $<1.0$. Ploidy of the leukaemic blasts is an important prognostic marker in ALL. High hyperdiploidy (DNA index $>1.16$ ), especially when it includes trisomy of chromosomes 4, 10, and 17 (so called 'triple trisomy'), is associated with good prognosis [5-7]. Survival rates increase to above $90 \%$ in patients with these good cytogenetic findings coupled with the other positive clinical features $[8,9]$. On the other hand, hypodiploidy (DI $<1.0$ ) is associated with poor outcomes and reduced survival rates down to $20-30 \%(1)$.

\section{Chromosomal Translocations}

Particular recurrent chromosomal translocations are associated with either a good or bad prognosis. The most important of the known translocations are: $\mathrm{t}(9 ; 22)(\mathrm{q} 34 ; \mathrm{q} 11)$ the BCR-ABL fusion that produces a foreshortened chromosome known as Philadelphia chromosome $(\mathrm{Ph})$ ALL and $\mathrm{t}(12 ; 21)$ (p12;q22) coding for a fusion of the ETV6 and RUNX1 proteins. The latter translocation is associated with a very good prognosis and includes $25 \%$ of the patients in Caucasian populations $[10,11]$. $(\mathrm{Ph}) \mathrm{ALL}$ has until recently been linked with poorer outcomes, but with intensive chemotherapy and the molecularly targeting drug Imatinib Mesylate (marketed by Novartis as Gleevec/Glivec) cure rates have increased up to $87 \%$ [12].

\section{Genetic Subtypes of ALL and Treatment Response}

Among children with B-lineage ALL, those with hypodiploidy, and the $\mathrm{t}(9 ; 22) / B C R-A B L, \mathrm{t}(4 ; 11) /$ IMLL-AF4 fusion generally have worse treatment outcomes, while hyperdiplioidy, TEL-AML1 fusion, and trisomy 4, 10, and 17 are associated with a favourable prognosis [13, 12]. Analysis of 706 children with B-lineage ALL signed up for four different treatment protocols at St Jude Children's Research Hospital in US over 15 years period revealed that patients with hyperdiploidy, TEL-AML1, and $\mathrm{t}(1 ; 19)$ / E2A-PBX1 had the best outcome. At the same time those with the $(9 ; 22) / B C R-A B L$, or $\mathrm{t}(4 ; 11) / M L L$ $A F 4$ had a very poor prognosis [13].

\section{Minimal Resisual Disease (MRD)}

MRD is one of the most important prognostic factors in ALL. By using rapid flow cytometric techniques or polymerase chain reaction (including RT-PCR (reverse transcription polymerase chain reaction) and QRT-PCR (quantitative reverse transcriptase polymerase chain reaction) and occasionally DNA PCR) we can detect one leukemic cell in $10^{2}-10^{4}$ normal cells. The significance of MRD is linked to a specific treatment regimen. MRD is usually validated early in therapy (i.e. end of the first 4-6 week period called Induction), and at the end of the second phase of therapy (Consolidation). MRD evaluation at the end of Induction aims to estimate the likelihood of relapse-free survival and address the efficacy of intensifying 
therapy in response to specific levels of MRD positivity or de-escalating the intensity of treatment when MRD is negative [1].

Recent studies have confirmed that MRD is the strongest predictor of outcome in childhood ALL [14]. Investigators of the Children's Oncology Group (COG) conducted a study involving 2143 children with B-lineage ALL. They monitored MRD in peripheral blood collected on day 8 and in bone marrow collected on day 29 (end of remission induction therapy). The presence of MRD $(0.01 \%$ or higher $)$ at either interval predicted a poorer outcome. MRD levels in the day 29 bone marrow were the strongest prognostic factors in their study [15]. Investigators of International Berlin-Frankfurt-Muenster (I-BFM) group described a 10 -year event-free survival of $16 \%$ for patients in the high-risk group (defined by MRD levels of $0.1 \%$ or higher on both days 33 and 78 ; $15 \%$ ) compared to $93 \%$ for the low-risk group of patients (defined by negative MRD at both time points; 43\%) [10].

In addition to measuring early response to therapy, MRD measurements can herald impending relapse, thus prompt the planning of salvage therapy or consideration of allogenic haematopoietic stem cell transplantation (HSCT). As the risk of relapse after HSCT is associated with levels of MRD before transplant, MRD assays can be used to determine the HSCT timing. Monitoring MRD post HSCT can be useful for guiding the administration of donor lymphocyte infusions or other agents. MRD also helps to select the optimal postremission treatment in patients who achieved second remission post relapse (i.e., chemotherapy versus HSCT) [14].

Based on clinical features at presentation and cytogenetic characteristics paediatric ALL patients can be classified into groups that can predict response to specific chemotherapy drugs and to complex regimens of medications [16]. By identifying lower risk groups of patients and reducing the intensity of their therapies, we are able to decrease the incidence of long-term side effects such as neurocognitive problems, infertility, secondary malignant neoplasms [13]. However, patients with high-risk ALL remain at increased risk for relapse and treatment-related reverse effects from intensified treatment. They also often suffer from longterm side effects. High-risk ALL patients are one of the biggest challenges of ALL treatment. Furthermore, medications used to ALL treatment have remained nearly unchanged over the last few decades. Therefore patients with ALL relapse are treated with greater intensity of the same drugs [3]. Modern treatment algorithms (current and proposed) incorporate patient's response factors including measurement of expression of genes important for drug metabolism and real-time pharmacokinetics. The search for specific signaling pathways and drugs specifically targeting the genetic defects of leukaemic cells could revolutionise management of this disease.

\section{Kinase Signaling in Paediatric Precursor-B ALL}

Protein kinases regulate most aspects of cell life and constitute one of the largest groups of genes. Molecular translocations resulting in impaired kinase signaling have been identified in several genetically defined ALL subgroups. In 2009 Russell et al. described translocations involving cytokine receptor-like factor 2 (CRLFT2): $\mathrm{t}(\mathrm{X} ; 14)(\mathrm{p} 22 ; \mathrm{q} 32)$ or $\mathrm{t}(\mathrm{Y} ; 14)(\mathrm{p} 11 ; \mathrm{q} 32)$ or deletions involving the pseudoautosomal region (PAR1), either $\operatorname{del}(\mathrm{X})(\mathrm{p} 22.33)$ or $\operatorname{del}(\mathrm{Y})(\mathrm{p} 11.32 \mathrm{p} 1132)$ that occur in $5 \%$ of ALL in children [3]. Overexpression of CRLFT2 was associated with activation of the JAK-STAT pathway and proliferation in B-cell progenitors. The report suggests the role of CRLFT2 in lymphoid transformation. In 2010 Harvey et al. analysed 207 high-risk patients and reported a cohort in which overexpression of CRLFT2, concurrent deletions of $I K Z F 1$, and other aberrations were associated with end free survival of approximately $15-20 \%$ and a gene-expression reflective of activated tyrosine kinase [17]. Molecular aberrations that affect JAK-STAT pathway, including mutations JAK2 and JAK1, are linked to several haematologic malignancies [3]. Because of the association between CRLFT2 overexpression and JAK mutations, patients with relapsed leukaemia who are known to have mutations either of CRLFT2 or JAK are eligible for enrolment in COG study ADVL1011 to receive a JAK inhibitor, INCB018424 (Ruxolitinib; Incyte Corporation) [3].

\section{Novel Therapies for Other Kinase-Dependent Signaling Pathways}

Other examples of signaling pathways and potential targeted therapies are the PI3K-Akt and Ras-MAPK prosurvival signaling pathways that are required for normal homeostasis in non-malignant cells. In 2010 Lee-Sherick et al. reported that the PI3K-Akt pathway is often upregulated in many lymphoid malignancies, leading to the development of targeted therapies against the mammalian target of rapamycin (mTOR) and the TOR complexes. It has been found that the inhibition of 
mTOR is effective in paediatric ALL. The results of the research have led to an evaluation of temsirolimus (CC1-779) in phase 1 clinical trials [18].

\section{Molecular Aberrations in Paediatric T-Lineage ALL}

T-ALL is associated with clinically aggressive features and poor treatment outcomes. Children with T-ALL are more likely to present with highrisk features compared with patients with precursor B-ALL. In 2009 Coustan-Smith et al. speculated that ALL directed therapies might induce less favourable response from T-lymphoblasts with stem-cell-like characteristics [19]. 30 samples banked at St Jude Children's Research Hospital in the US were identified to have early T-precursor (ETP) antigen profiles which were characterized by CD1a (-), CD8 (-), CD5 (weak) with stem cell or myeloid markers. Those patients with ETP had a $75 \%$ relapse rate [19].

\section{Discovery of Genes Associated with Treatment Response}

Several research studies used in vitro drug sensitivity testing to identify genes associated with drug resistance. Lugthart et al. determined in vitro drug sensitivity of leukaemic cells from 441 patients and identified 45 genes differentially expressed in ALL showing crossresistance to prednisolone, vincristine, asparaginase and daunorubicin. The expression of these genes was markedly associated with treatment outcome in 2 separated cohorts, identifying a group of patients with a significantly inferior outcome [20]. In 2006 Holleman et al. studied the link between genes encoding key regulators of apoptosis, in vitro drug resistance and treatment outcome in ALL. The study revealed a significant association between increased expression of the anti-apoptotic gene MCL1 and prednisolone resistance, whereas that of the pro-apoptotic gene HRK was associated with increased asparaginase sensitivity. Increased expression of another pro-apoptotic gene, $B C L 2 L 13$, was associated with a higher resistance to asparaginase and worse treatment outcome [19.21].

\section{Polymorphism in Drug Metabolising Genes and Treatment Response}

Variation in the expression and function of genes involved in drug metabolism has been associated with treatment response in children with
ALL. For example, genetic polymorphisms and the activity of thiopurine methyltransferase, an enzyme that inactivates thiopurines, impact response to this class of drugs. Patients with heterozygous or homozygous deficiency are at risk of serious toxic effect on the bone marrow stroma. The enzyme deficiency is associated with a higher risk of therapy related acute myeloid leukaemia and radiation-induced brain tumours in patients treated with thiopurines. However, patients with increased enzyme activity might be at a greater risk of relapse due to reduced exposure of leukaemic cells to active drug metabolites [14]. In 2011 Peregud-Pogorzelski et al. conducted a multicentre study and investigated the association between thiopurine S-methyltransferase genotype, 6-Mercaptopurine (6-MP) dose adjustments, and the incidence of adverse effects in patients. Using PCR/allele-specific amplification and PCR/RFLP (restriction fragment length polymorphism) investigators analysed a total of 203 children with ALL. The control group consisted of 394 healthy volunteers. Those patients with $\mathrm{TPMT}^{*} 3 \mathrm{~A}$ and $\mathrm{TPMT}^{*} 3 \mathrm{C}$ alleles required more frequent 6-MP dose reduction due to side effects such as anaemia and/or thrombocytopenia, leucopenia with respiratory tract infection. The results indicate that TPMT genotype influences the safety and efficacy of ALL treatment and genotype information may therefore be useful for optimizing 6-MP therapy [22]. De Jonge et al. investigated the influence of polymorphisms of genes involved in folate metabolism on methotrexate sensitivity in vitro in 157 cases of paediatric ALL. Those with the metylenetetrahydrofolate reductase (MTHFR) $1298 \mathrm{AC}$ variant and those with the methionine synthase reductase (MTRR) $66 \mathrm{G}$-allele had a reduced sensitivity [14].

\section{AML}

Acute Myeloid Leukaemia (AML) accounts for $15-20 \%$ of the acute leukaemias in children. However, AML is responsible for nearly twice that percentage of deaths from leukaemia in childhood $[11,23]$. As observed in patients with ALL, paediatric AML is quite varied and heterogenous in its presentation, biology and treatment. In a process similar to the one described for ALL, children diagnosed with AML are assigned into risk-stratified treatment groups. Initial WBC and CNS involvement do not appear to have a similar importance in determining risk status. There are significant differences in cure rates for various treatment response groups and genetic subsets [3]. Following the UK MRC (Medical Research Council) AML 10 clinical trial, risk group stratification was improved based 
on the identification of patient groups with a complete response ( $<5 \%$ blasts), partial response $(5 \%$ $15 \%$ blasts), or resistant disease ( $>15 \%$ blasts) after the first course of induction failure that consisted of daunomycin, cytarabine and etoposide [3]. Following further intensification, patients with endinduction complete response, partial response, or resistant disease had overall survival rates 53\%, $44 \%$ and $22 \%$, respectively [3].

Based on cytogenetic analysis 3 risk groups have been identified among children with AML: 1) a favourable risk group that consists of $\mathrm{t}(15 ; 17)[P M L$ $R A R \alpha], \mathrm{t}(8 ; 21)[A M L 1-E T O]$, and inv16[CBF $\beta$ $M Y H 11]$; 2) an intermediate group including $M L L$ chimeric fusion genes or a normal karyotype; and 3) a high risk group consisting of $-5 / \operatorname{del}(5 q),-7 /$ $/ \operatorname{del}(7 \mathrm{q})$, inv3/t, $(3,3),+8$, and complex karyotypes. Low expression of the ATRX gene and high expression of the RUNX3 gene are other high risk cytogenetic markers [3].

Fms-like tyrosine kinase receptor-3 (FLT3) and its ligand are important for normal haematopoiesis. Internal tandem duplications (ITDs) in exons 14 and/or 15 lead to constitutive receptor activation, and 'activating loop' mutations envolving exon 20 are the most common somatic mutation observed in AML (3). Approximately $20 \%$ of children with AML are affected by mutations of FLT. Study conducted by Kondo et al. in 1999, showed that among children with newly diagnosed AML those with FLT3/ITDs had an 8-year overall survival and event-free survival rates of $14 \%$ and $7 \%$, respectively in compare to $50 \%$ and $44 \%$ for patients without the FLT3/ITD molecular aberrancy [24]. Following induction therapy, $75-90 \%$ of all children diagnosed with AML enter into first remission and approximately $50 \%$ are cured of their disease [3]. Remission induction rates are lower, approximately $70 \%$, for high risk patients and heightened chance of disease recurrence depends on related or unrelated allogenic stem cell transplantation in first remission. If a suitable donor is not found, relapse continues to be a common problem, calling for novel agents or targeted therapies. Studies of FLT3-kinase signalling in AML have led to the development of agents with selective inhibitory activity. Currently, there are several FLT3-inhibitory agents under development. However, CEP-701 (Lestaurtinib) has been studied the most extensively so far in clinical trials for infants, children and adults [3]. A pilot study of lestaurtinib in combination with cytarabine and idarubicin in relapsed or refractory FLT-3 mutant AML has been completed recently. The aim of that study was to investigate the dose-limiting toxicities of lestaurtinib in a nonrandomised setting for patients under the age of 30 years. Following an initial safety phase, the study entered an efficacy phase to asses if lestaurtinib could be provided in sufficient dose to adequately inhibit FLT3 kinase in patients. The study passed its safety assessment, and recently closed after completing its goals for an overall assessment for lestaurtinib efficacy. Six other FLT3 inhibitors are currently being evaluated in clinical trials [25]. Unfortunately, AML remains a far more difficult disease to treat and cure than ALL.

\section{Concluding Remarks}

The outcome of children with leukaemia has improved significantly over the last few decades. New treatment protocols are designed to maintain a high cure rate for these children while reducing toxicity. Future targets for treatment are expected to emerge, based on the molecular genetics of leukaemia. Such a biology-driven approach to risk stratification and introduction of novel therapies should continue to improve the success of first line treatments whilst minimising the overall burden of therapy.

\section{References}

[1] Margolin JF: Molecular diagnosis and risk-adjusted therapy in pediatric hematologic malignancies: a primer for pediatricians. Eur J Pediatr 2011, 170, 419-425.

[2] Pieters R, Carroll WL: Biology and treatment of acute lymphoblastic leukemia. Hematol Oncol Clin North Am 2010, 24, 1-18.

[3] Winter SS: Pediatric acute leukemia therapies informed by molecular analysis of high-risk disease. Hematology Am Soc Hematol Educ Program 2011, 366-373.

[4] Stubbs MC, Kim YM, Krivtsov AV, Wright RD, Feng Z, Agarwal J, Kung AL, Armstrong SA: MLL-AF9 and FLT3 cooperation in acute myelogenous leukemia: development of a model for rapid therapeutic assessment. Leukemia 2008, 22, 66-77.

[5] Harris MB, Shuster JJ, Carroll A, Look AT, Borowitz MJ, Crist WM, Nitschke R, Pullen J, Steuber CP, Land VJ: Trisomy of leukemic cell chromosomes 4 and 10 identifies children with B-progenitor cell acute lymphoblastic leukemia with a very low risk of treatment failure: a Pediatric Oncology Group study. Blood 1992, 79, 3316-3324.

[6] Heerema NA, Sather HN, Sensel MG, Heerema NA, Zhang T, Hutchinson RJ, Nachman JB, Lange BJ, Steinherz PG, Bostrom BC, Reaman GH, Gaynon PS, Uckun FM: Prognostic impact of trisomies of chromosomes 10, 17, and 5 among children with acute lymphoblastic leukemia and high hyperdiploidy (> 50 chromosomes). J Clin Oncol 2000, 18, 1876-1887. 
[7] Li ZY, Liu DP, Liang CC: New insight into the molecular mechanisms of MLL-associated leukemia. Leukemia 2005, 19, 183-190.

[8] Chauvenet AR, Martin PL, Devidas M, Chauvenet AR Linda SB, Bell BA, Kurtzberg J, Pullen J, Pettenati MJ, Carroll AJ, Shuster JJ, Camitta B: Antimetabolite therapy for lesser-risk B-lineage acute lymphoblastic leukemia of childhood: a report from Children's Oncology Group Study P9201. Blood 2007, 110, 1105-1111.

[9] Hunger SP, Winick NJ, Sather HN, Carroll WL: Therapy of low-risk subsets of childhood acute lymphoblastic leukemia: when do we say enough? Pediatr Blood Cancer 2005, 45, 876-880.

[10] Flohr T, Schrauder A, Cazzaniga G, Flohr T, Panzer-Grümayer R, van der Velden V, Fischer S, Stanulla M, Basso G, Niggli FK, Schäfer BW, Sutton R, Koehler R, Zimmermann M, Valsecchi MG, Gadner H, Masera G, Schrappe M, van Dongen JJ, Biondi A, Bartram CR; International BFM Study Group (I-BFM-SG): Minimal residual disease-directed risk stratification using real-time quantitative PCR analysis of immunoglobulin and T-cell receptor gene rearrangements in the international multicenter trial AIEOP-BFM ALL 2000 for childhood acute lymphoblastic leukemia. Leukemia 2008, 22, 771-782.

[11] Rubnitz JE, Gibson B, Smith FO: Acute myeloid leukemia. Hematol Oncol Clin North Am 2010, $24,35-63$.

[12] Schultz KR, Bowman WP, Aledo A, Slayton WB, Sather H, Devidas M, Wang C, Davies SM, Gaynon PS, Trigg M, Rutledge R, Burden L, Jorstad D, Carroll A, Heerema NA, Winick N, Borowitz MJ, Hunger SP, Carroll WL, Camitta B: Improved early event-free survival with imatinib in Philadelphia chromosome-positive acute lymphoblastic leukemia: a children's oncology group study. J Clin Oncol 2009, 27, 5175-5181.

[13] Pui CH, Robison LL, Look AT: Acute lymphoblastic leukaemia. Lancet 2008, 371, 1030-1043.

[14] Campana D: Molecular determinants of treatment response in acute lymphoblastic leukemia. Hematology Am Soc Hematol Educ Program 2008, 366-373.

[15] Borowitz MJ, Devidas M, Hunger SP, Bowman WP, Carroll AJ, Carroll WL, Linda S, Martin PL, Pullen DJ, Viswanatha D, Willman CL, Winick N, Camitta BM; Children's Oncology Group: Clinical significance of minimal residual disease in childhood acute lymphoblastic leukemia and its relationship to other prognostic factors: a Children's Oncology Group study. Blood 2008, 111, 5477-5485.

[16] Mullighan CG, Downing JR: Genome-wide profiling of genetic alterations in acute lymphoblastic leukemia: recent insights and future directions. Leukemia 2009, 23, 1209-1218.

[17] Ensor HM, Schwab C, Russell LJ, Richards SM, Morrison H, Masic D, Jones L, Kinsey SE, Vora AJ, Mitchell CD, Harrison CJ, Moorman AV: Demographic, clinical, and outcome features of children with acute lymphoblastic leukemia and CRLF2 deregulation: results from the MRC ALL97 clinical trial. Blood 2011, 117, 2129-2136.

[18] Lee-Sherick AB, Linger RM, Gore L, Keating AK, Graham DK: Targeting paediatric acute lymphoblastic leukaemia: novel therapies currently in development. Br J Haematol 2010, 151, 295-311.

[19] Coustan-Smith E, Mullighan CG, Onciu M, Behm FG, Raimondi SC, Pei D, Cheng C, Su X, Rubnitz JE, Basso G, Biondi A, Pui CH, Downing JR, Campana D: Early T-cell precursor leukaemia: a subtype of very highrisk acute lymphoblastic leukaemia. Lancet Oncol 2009, 10, 147-156.

[20] Lugthart S, Cheok MH, den Boer ML, Yang W, Holleman A, Cheng C, Pui CH, Relling MV, Janka-Schaub GE, Pieters R, Evans WE: Identification of genes associated with chemotherapy crossresistance and treatment response in childhood acute lymphoblastic leukemia. Cancer Cell 2005, 7, 375-386.

[21] Holleman A, Cheok MH, den Boer ML, Yang W, Veerman AJ, Kazemier KM, Pei D, Cheng C, Pui CH, Relling MV, Janka-Schaub GE, Pieters R, Evans WE: Gene-expression patterns in drug-resistant acute lymphoblastic leukemia cells and response to treatment. N Engl J Med 2004, 351, 533-542.

[22] Peregud-Pogorzelski J, Tetera-Rudnicka E, Kurzawski M, Brodkiewicz A, Adrianowska N, Mlynarski W, Januszkiewicz D, Drozdzik M: Thiopurine S-methyltransferase (TPMT) polymorphisms in children with acute lymphoblastic leukemia, and the need for reduction or cessation of 6-mercaptopurine doses during maintenance therapy: the Polish multicenter analysis. Pediatr Blood Cancer 2011, 57, 578-582.

[23] Meshinchi S, Arceci RJ: Prognostic factors and risk-based therapy in pediatric acute myeloid leukemia. Oncologist 2007, 12, 341-355.

[24] Kondo M, Horibe K, Takahashi Y, Matsumoto K, Fukuda M, Inaba J, Kato K, Kojima S, Matsuyama T: Prognostic value of internal tandem duplication of the FLT3 gene in childhood acute myelogenous leukemia. Med Pediatr Oncol 1999, 33, 525-529.

[25] Wiernik PH: FLT3 inhibitors for the treatment of acute myeloid leukemia. Clin Adv Hematol Oncol 2010, 8, 429-436, 444.

\section{Address for correspondence:}

Elwira Szychot

Haematology and Oncology Department

Great Ormond Street Hospital for Children NHS Foundation Trust

Great Ormond Street

London WC1N 3JH

United Kingdom

E-mail: szychelv@doctors.org.uk

Conflict of interest: None declared

Received: 2.09.2013

Revised: 22.09.2013

Accepted: 9.06.2014 